\title{
Lumbar Intervertebral Disc Calcification: A Case Report
}

\author{
Umit Eroglu*, Fatih Yakar and Hasan Caglar Ugur \\ Department of Neurosurgery, Ankara University School of Medicine,Turkey
}

Submission: March 27, 2017; Published: April 11, 2017

*Corresponding author: Umit Eroglu, Department of Neurosurgery, Ankara University School of Medicine, Turkey, Tel: +0903125082598/+0905056189407; Fax: +090312508244; Email: umitkovikeroglu@hotmail.com

\begin{abstract}
Intervertebral disc calcification is an uncommon cause of spinal pain and really rare in lumbar disc levels. The certain etiology still remains uncertain. Most of cases are asymptomatic and are diagnosed incidentally in routine scanning or during evaluation of non-specific clinical complaints. A 63-year-old male presented with waist and both legs pain. There was no definite history of trauma or infection. Imaging of the lumbar spine showed calcification of the intervertebral disc at L1-2 level. The patient was kept on medical therapy. The complaints showed near-complete resolution on 3-month follow-up.
\end{abstract}

Keywords: Disc calcification; Lumbar; Nucleus pulposus

Abbrevations: IVDC: Intervertebral Disc Calcification; CT: Computed Tomography; MRI: Magnetic Resonance Imagination; X-ray: Direct Radiography

\section{Introduction}

Intervertebral disc calcification (IVDC) is the accumulation of calcium pyrophosphate dihydrate or hydroxyapatite crystals in the nucleus pulposus or annulus fibrosus. Incidence of IVDC increase with age and narrowing disc space. Although IVDC is seen with the several systemic diseases and immobilization; probably the most common causes in elderly patients are intervertebral disc degeneration and aging [1].

The disease is usually diagnosed incidentally. It is diagnosed more frequently in patients who are 60 years or older. It also may be seen in patients who are 20 years or younger but in this group, spontaneous regression is a possible. In this paper, we report a 63-year-old male patient was presented with the rarely seen IVDC and dicuss clinical and radiological findings.

\section{Case Report}

63-year-old male patient admitted to our institution with pain in his waist and both legs. Physical and neurological examinations were normal. Laboratory findings were in normal range. The patient had no trauma or surgery in his history. Thyroid and parathyroid hormones profile were normal. There was no diagnosis of osteoporosis. On the magnetic resonance imagination (MRI), at the L1-2 level discus was hypointense (Figure 1), and intervertebral disc calcification was seen in lumbar computed tomography (CT) (Figure 2a \& 2b). When evaluated with CT, initial clinical findings were consistent with the intervertebral disc calcification. The clinic signs of the patient was thought to be due to lumbar spinal stenosis secondary to the of L2-3, L3-4, L4-5 levels disc herniations. Non steroidal inflammatory drug medication was prescribed and resting was recommended for the patient. The patient's complaints were diminished in short notice.

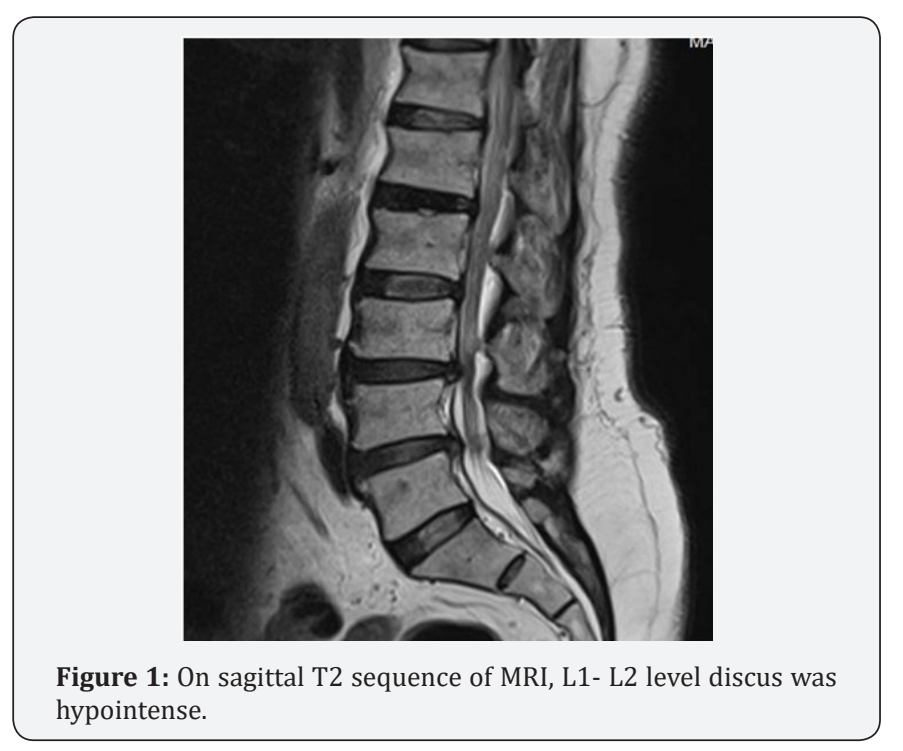




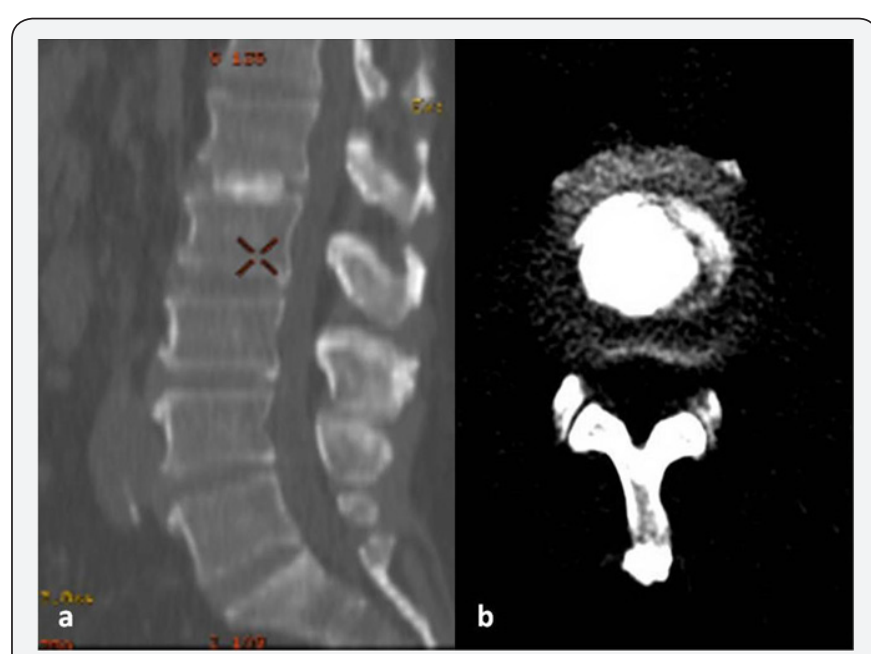

Figure 2a \&2b: (a) Non contrast CT scan of lumbar spine showing calcification at level L1- L2 sagittal section (b)axial section of level L1-L2.

\section{Discussion}

IVDC is a condition with calcium pyrophosphate dihydrate and or hydroxyapatite collection presented in nucleus pulposus or annulus fibrosus [2]. An inflammatory process is needed to start in nucleus pulposus to realize this condition [3]. It's thought that infection and blood flow disorders, and posttraumatic inflammation cause this process [2-5]. Nucleus pulposus calcification can be asymptomatic or start with fever accompanied with local pain. The pain disappears spontaneously afterwards. Intradiscal calcification resorbs and resorbtion can be seen with a completed disc protrusion. $80 \%$ of the patients admit with back pain and leg pain. Usually, calcified discs herniate slightly more than non-calcified discs [2].

Neurological signs can be seen in the acute phase as a result of disc protrusion that cause radix compression or spinal cord compression [2-4]. It's thought that, in our case; back and bilateral leg pain occured as a result of spondylolistezis. There were no signs of inflammation or neurological symptoms.

Disc calcification is seen in 5-6\% with conventional radiography [1]. Hyperparathroidism and thalassemia constitute a high-risk group for intradiscal calcification. In autopsy series, intradiscal calcifications were detected in $80 \%$ of the patients. $8 \%$ of the cases are in the upper thoracic level, $17 \%$ is midthoracic and $60 \%$ is at the lower thoracic level [6]. Gerlach et al. [4] noticed that multiple level disc calcification is present in $30-40 \%$ of the patients.
Calcification of the oval-shaped nucleus pulposus can seen on the intervertebral disc with direct radiography (X-ray) on radiological imagination $[7,8]$. CT scan is more valuable than MRI in showing intervertebral calcification but MRI is more sensitive in showing inflammation on the herniated disc with a reduction in disc signal intensity [2,4-7]. Degenerated intervertebral disc appears hypointense on T2 sequence MRI [2]. Calcification and vacuum phenomenon are inseparable via the hypointensity differences on the MRI [2]. CT scan defines disc calcifications better than other imaging methods [3]. Anti-inflammatory and basic analgesic drugs are used for the treatment of idiopathic intervertebral disc calcification [2]. If neurological symptoms are also present, surgical decompression can be planned. If it's located even in the servical region, excision may be planned [57]. In adult patients, lumbar intervertebral disc calcification is an idiopathic, rare condition; which is usually diagnosed as a result of admission to the hospital for a nonspecific clinical routine inspection or with non-specific and mild complaints. IVDC has a good prognosis and no cause is yet specified for this disorders.

\section{References}

1. Weinberger A, Myers AR (1978) Intervertebral disc calcification in adults: a review. Semin Arthritis Rheum 8(1): 69-75.

2. Bagatur AE, Zorer G, Centel T (2001) Natural history of paediatric intervertebral disc calcification. Arch Orthop Trauma Surg 121(10): 601-603.

3. Dias MS, Pang D (1991) Juvenile intervertebral disc calcification: recognition, management, and pathogenesis. Neurosurgery 28(1): 130-135.

4. Gerlach R, Zimmermann M, Kellermann S, Lietz R, Raabel A, et al. (2001) Intervertebral disc calcification in childhood: a case report and review of the literature. Acta Neurochir 143(1): 89-93.

5. Harvet G, De PL, Neven B, Mary P, Letamendia RE, et al. (2004) Paediatric intervertebral calcifications: two cases report and review of the literature. Arch Pediatr 11(12): 1457-1461.

6. Chanchairujira K, Chung CB, Kim JY, Papakonstantinou O, Lee MH, et al. (2004) Intervertebral disc calcification of the spine in an elderly population: radiographic prevalence, location, and distribution and correlation with spinal degeneration. Radiology 230(2): 499-503.

7. Falcone L, Rossiello P, Addetta DI, Martino F (2006) Idiopathic intervertebral disc calcification in children: the role of diagnostic imaging. Reumatismo 58(1): 62-65.

8. Morris IM, Sheppard L (1986) The persistence of clinical and radiological features after intervertebral disc calcification of childhood. Br J Rheumatol 25(2): 219-221. 
This work is licensed under Creative Commons Attribution 4.0 License DOI: 10.19080/NAPDD.2017.01.555552

\section{Your next submission with Juniper Publishers} will reach you the below assets

- Quality Editorial service

- Swift Peer Review

- Reprints availability

- E-prints Service

- Manuscript Podcast for convenient understanding

- Global attainment for your research

- Manuscript accessibility in different formats ( Pdf, E-pub, Full Text, Audio)

- Unceasing customer service

Track the below URL for one-step submission https://juniperpublishers.com/online-submission.php 